\title{
ESTUDO DO EFEITO DA ADIÇÃO DE SORO DE QUEIJO NA QUALIDADE MICROBIOLÓGICA DO DOCE DE LEITE PASTOSO
}

\author{
STUDY ON THE EFFECT OF THE ADDITION OF WHEY IN THE \\ MICROBIOLOGICAL QUALITY OF THE DULCE DE LECHE OF PASTY \\ ${ }^{1}$ Grasiele Scaramal Madrona; ${ }^{2}$ Marta Fernanda Zotarelli; ${ }^{3}$ Rosângela Bergamasco \\ ${ }^{1,2,3}$ Univesidade Estadual de Maringá - Maringá - Brasil \\ 1'gsmadrona@uem.br; 르zotarelli@hotmail.com; ${ }^{3}$ rosangela@deq.uem.br
}

\begin{abstract}
Resumo
A estabilidade microbiológica do doce de leite depende principalmente do controle higiênico do processo e deve ser atingida para evitar desenvolvimento de bolores e leveduras que podem ocorrer mesmo em condições de alta pressão osmótica do produto. O presente trabalho tem como principal objetivo avaliar as condições microbiológicas de diferentes amostras de doce de leite produzidas com adição de soro de queijo. Na maioria das amostras não foi detectada a presença de bolores e leveduras e de staphylococcus aureus coagulase positiva, encontrando-se valores inferiores a $1 \times 10^{2} \mathrm{UFC} / \mathrm{g}$. Sendo assim todas as amostras encontram-se aptas para o consumo humano e dentro dos padrões da legislação.
\end{abstract}

Palavras-chave: doce de leite pastoso, soro de queijo, microbiologia.

\section{Introdução}

O doce de leite é um importante produto do setor de laticínios, produzido e comercializado principalmente no Brasil e na Argentina (MACHADO, 2005). Tecnologicamente o doce de leite se enquadra entre os produtos de leite conservados por evaporação e adição de açúcar, de modo que, em função da alta pressão osmótica criada pode ser conservado à temperatura ambiente (ARES, 2006). O doce de leite apresenta consistência cremosa ou pastosa e homogênea, sem grumos, flocos ou bolhas, cor caramelo brilhante proveniente da Reação de Mailard, aroma próprio e sabor característico.

Sabe-se que algumas indústrias utilizam soro de queijo in natura na produção do doce de leite, pois a legislação vigente permite a adição de derivados lácteos. Outra alternativa seria a utilização de soro em pó. A produção de soro em pó é uma opção para utilização do valor nutricional do soro de queijo in natura, que quando descartado sem nenhum tratamento se torna um problema ambiental (SIVIERI, 2002). 
As características microbiológicas do doce de leite são: máximo de 100 UFC/g tanto para Staphylococcus coagulase positiva, quanto para Contagem de Bolores e Leveduras, conforme a portaria $\mathrm{n}^{0}$ 354, de 04 de setembro de 1997 (BRASIL, 2007).

Não se deve considerar para uma avaliação microbiológica apenas a parte de produção do doce de leite, a embalagem deve proteger contra a perda de umidade e dificultar a passagem de oxigênio, além de impedir a contaminação microbiológica (MARTINS \& LOPES, 1981). Algumas características intrínsecas do doce de leite garantem uma melhor conservação do produto. Como exemplo podemos citar a alta concentração de sólidos no produto que resulta em uma atividade de água (Aw) normalmente abaixo de $0,85 \%$, constitui o principal fator de conservação do doce de leite. Os cuidados com a higiene no processamento e no momento do envase contribuem significativamente para a obtenção de produtos com boa qualidade microbiológica. Alguns estudos têm relacionado a ocorrência de intoxicação alimentar com a presença de Staphylococcus coagulase positiva (PIMENTEL, et al., 2002) como também, relacionado com riscos à saúde humana (CHUNHA NETO et al., 2002) em derivados lácteos, o que contribui para elucidar a necessidade de um monitoramento constante nos processos de higienização dos equipamentos de processo, das superfícies que entram em contato direto com os alimentos, dos manipuladores e do ar dos ambientes das indústrias.

O objetivo deste trabalho foi elaborar um doce de leite com adição de diferentes concentrações de soro de queijo in natura ou pó e avaliar as condições microbiológicas.

\section{Material e Métodos}

Para elaboração do doce de leite utilizou-se leite UHT da marca Parmalat, bicarbonato de sódio PA- ACS, amido de milho fabricado pela Unilever Bestfoods Brasil LTDA., açúcar do tipo cristal da usina Guarani, soro de queijo in natura tipo frescal, fornecido pelo Colégio Regina Mundi, localizado no município de Maringá-PR. O soro em pó era proveniente da empresa Alibra Ingredientes LTDA, localizada no município de Campinas-SP. Optou-se por utilizar soro de queijo por ser permitido pela legislação vigente de doce de leite a adição de sólidos de origem láctea. O soro in natura, foi utilizado por ser uma matéria-prima sem custo nenhum e abundante. A adição de soro em pó ao doce de leite é um estudo inédito e proporcionará um comparativo com o produto obtido pela adição de soro in natura. Contudo, deve-se atentar ao fato do soro em pó ser um produto mais caro e menos abundante.

A fabricação do doce de leite seguiu o processo tradicional proposto por (HOSKEN, 1969), descrito na Figura 1. O leite foi substituído parcialmente por soro de queijo in natura ou em pó. Foram produzidos cinco tipos diferentes de doce de leite. O “doce de leite A" tem em sua 
composição 0\% de soro em pó e 100\% de leite, o “doce de leite B” tem 25\% de soro in natura e $75 \%$ de leite, o “doce de leite C” $50 \%$ de soro in natura e 50\% de leite, o “doce de leite D” tem $25 \%$ de soro em pó e $75 \%$ de leite e o “doce de leite E” $50 \%$ de soro em pó e $50 \%$ de leite. Os outros ingredientes encontram-se nas mesmas concentrações.

Figura 1 - Fluxograma de processamento do doce de leite

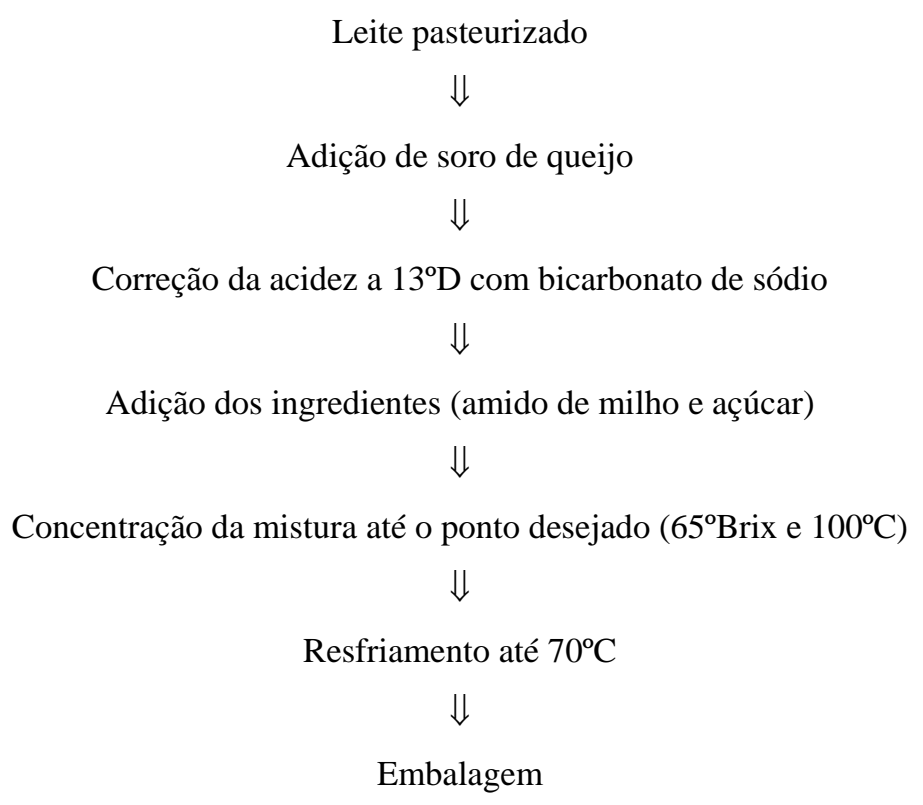

As amostras foram analisadas no Laboratório de Microbiologia de Alimentos da Universidade Estadual de Maringá em relação à Contagem de Bolores e Leveduras, empregando o método de contagem em placas em meio Ágar Dicloram Glicerol 18\% (DG18), seguindo a metodologia, proposta por VANDERZANT \& SPLITTSTOESSER (1992). Em relação à presença de Staphylococcus coagulase positiva, empregou-se a metodologia proposta por VANDERZANT \& SPLITTSTOESSER (1992). Os doces obtidos pelos diferentes tratamentos foram avaliados mensalmente, durante 3 meses.

\section{Resultados e discussão}

Segundo a portaria $n^{\circ}$ 354, de 04 de setembro de 1997 (BRASIL, 2007) é permitido no doce leite pastoso um valor máximo de $1 \times 10^{2} \mathrm{UFC} / \mathrm{g}$ para fungos e leveduras e para Staphylococcus coagulase positiva. Para as análises de Staphylococcus coagulase positiva, independente do tipo de soro e da concentração de soro de queijo utilizada, todos os doces de leite encontram-se dentro dos padrões da legislação, durante todo o período de estocagem. Isso indica que todo o processo, incluindo momento de envase, foi bem conduzido e que as embalagens foram esterilizadas 
adequadamente. A Tabela 1 apresenta a contagem de Staphylococcus coagulase positiva.

Tabela 1 - Contagem de Staphylococcus coagulase positiva (UFC/g doce) de doce de leite durante o período de estocagem

\begin{tabular}{|c|c|c|c|c|}
\hline Amostras & Mês 0 & Mês 1 & Mês 2 & Mês 3 \\
\hline Doce A & $<1 \times 10^{2}$ & $<1 \times 10^{2}$ & $<1 \times 10^{2}$ & $<1 \times 10^{2}$ \\
\hline Doce B & $<1 \times 10^{2}$ & $<1 \times 10^{2}$ & $<1 \times 10^{2}$ & $<1 \times 10^{2}$ \\
\hline Doce C & $<1 \times 10^{2}$ & $<1 \times 10^{2}$ & $<1 \times 10^{2}$ & $<1 \times 10^{2}$ \\
\hline Doce D & $<1 \times 10^{2}$ & $<1 \times 10^{2}$ & $<1 \times 10^{2}$ & $<1 \times 10^{2}$ \\
\hline Doce E & $<1 \times 10^{2}$ & $<1 \times 10^{2}$ & $<1 \times 10^{2}$ & $<1 \times 10^{2}$ \\
\hline
\end{tabular}

A Tabela 2 apresenta a contagem de bolores e leveduras (UFC/g doce) dos doce de leite durante o período de estocagem.

Tabela 2 - Contagem de bolores e leveduras (UFC/g doce) nos doces de leite analisados durante o período de estocagem

\begin{tabular}{c|cccc}
\hline Amostras & Mês 0 & Mês 1 & Mês 2 & Mês 3 \\
\hline Doce A & $<1 \times 10^{2}$ & $<1 \times 10^{2}$ & $<1 \times 10^{2}$ & $<1 \times 10^{2}$ \\
Doce B & $<1 \times 10^{2}$ & $<1 \times 10^{2}$ & $<1 \times 10^{2}$ & $<1 \times 10^{2}$ \\
Doce C & $<1 \times 10^{2}$ & $<1 \times 10^{2}$ & $<1 \times 10^{2}$ & $<1 \times 10^{2}$ \\
Doce D & $<1 \times 10^{2}$ & $<1 \times 10^{2}$ & $<1 \times 10^{2}$ & $<1 \times 10^{2}$ \\
Doce E & $<1 \times 10^{2}$ & $<1 \times 10^{2}$ & $<1 \times 10^{2}$ & $1 \times 10^{2}$ \\
\hline
\end{tabular}

Apesar do crescimento verificado em uma das amostras, todas elas encontram-se abaixo do limite estabelecido pela legislação. Observa-se que as amostras de doce de leite apresentaram uma boa qualidade microbiológica, entretanto, a ocorrência de fungos e leveduras pode estar relacionada a atividade de água (Aw) do doce de leite, uma vez que esta estava abaixo de 0,85\%, faixa na qual esses microorganismos se desenvolvem, ou pelo fato do armazenamento do produto ter sido à temperatura ambiente por um longo período de tempo.

SOUZA et al. (2002) avaliaram 18 amostras de doce de leite de búfala e observaram que apenas $11 \%$ das amostras apresentaram resultados superiores a $1 \times 10^{3} \mathrm{UFC} / \mathrm{g}$ doce para bolores e leveduras, o que revela uma boa qualidade dos doces de leite de búfala produzidos na Ilha do Marajó - PA.

Outro fator que pode influenciar a qualidade microbiológica do doce de leite é o emprego de amido de milho modificado, uma vez que este proporciona maior retenção de água, interferindo na estabilidade. KONKEL et al. (2004) observaram que com o aumento do teor de amido de milho modificado, houve um aumento da umidade do doce de leite, reduzindo o período de estocagem. 


\title{
4. Conclusão
}

Os resultados obtidos para as análises microbiológicas de Staphylococcus coagulase positiva e bolores e leveduras evidenciaram que não há problema algum na utilização de soro de queijo in natura ou em pó na produção de doce de leite. Pode-se afirmar ainda que as boas condições higiênico-sanitárias influenciam nesse resultado.

Há uma grande heterogeneidade na qualidade do doce de leite produzido comercialmente, a substituição do leite pelo de soro de queijo in natura ou em pó significa para a indústria diminuição nos custos de fabricação e uma forma racional de aproveitamento deste produto secundário que apresenta excelente valor nutritivo.

O soro de queijo in natura ou em pó pode ser utilizado no processamento do doce de leite pastoso mesmo em altas concentrações (50\%), sem causar alteração na qualidade microbiológica do produto.

\begin{abstract}
The microbiology stability of dulce de leche depends mainly on the hygienic control of the process, and should be achieved to avoid the development of mould and yeast that can happen even in conditions of high osmotic pressure of the product. This work has as main objective the evaluation of the microbiologic conditions of different samples of dulce de leche produced with addition of whey. In most of the samples, the presence of mould, yeast and Staphylococcus positive coagulase was not detected, obtaining values lower than $1 \times 10^{2} \mathrm{UFC} / \mathrm{g}$. Therefore, all the samples were found to be acceptable for human consumption, as well as in accordance to the legislation standards.
\end{abstract}

Key-words: dulce de leche, whey, microbiology.

\section{Referências}

ARES, G.; GIMENEZ, A.; GAMBARO, A. Preference mapping of Dulce de Leche. Journal of Sensory Studies, v.21, n.6, p.553-571, 2006.

BRASIL. Ministério da Agricultura e do Abastecimento, Secretaria de Defesa Agropecuária, Departamento de Inspeção de Produtos de Origem Animal. Portaria No 354, de 4 de setembro de 1997. Disponível em:

http://www.agricultura.gov.br/das/dipoa/port354.html Acesso em: 29 de janeiro de 2007.

CUNHA NETO, A.; SILVA, C.G.M.; STAMFORD, T.LM. Staphylococcus enteroxigênicos em alimentos in natura e processados no estado de Pernambuco, Brasil. Ciência e Tecnologia de Alimentos, v.3, n.22, p.263-271, 2002.

HOSKEN, F.S. Doce de leite - Durabilidade e cristalização. Revista do Instituto de Laticínios Cândido Tostes, v.24, n.147, p.10-17, 1969.

KONKEL, F.E.; OLIVEIRA, S.M.R.; SIMÕES, D.R.S.; DEMIATE, I.M. Avaliação Sensorial de Doce de Leite Pastoso com Diferentes Concentrações de Amido. Ciência e Tecnologia de Alimentos, v.24, n.2, p. 249-254, 2004.

MACHADO, L. M. P. Uso de soro de queijo e amido de milho modificado na qualidade do doce de leite pastoso. 170p. Tese (Doutorado em Tecnologia de alimentos) Faculdade de Engenharia de Alimentos, Universidade Estadual de Campinas, 2005. 
MARTINS, J.F.P.; LOPES, C.N. Doce de leite: Aspectos da tecnologia de fabricação. Instruções Técnicas Instituto de Tecnologia de Alimentos, n.18, p.1-37, 1981.

PIMENTEL, E.F.; DIAS, R.S.; CARMOS, L.S.; GLORIA, M.B.A. Presença de Staphylococcus sp enterotoxigênico e de enterotoxinas em queijo ralado. Revista do Instituto de Laticínios Cândido Tostes, v. 57, n.327, p.227-229, 2002.

SIVIERI, K.; OLIVEIRA, M.N.; Avaliação da Vida-de-Prateleira de Bebidas Lácteas Preparadas com "Fat Replacers” (Litesse e Dairy-Lo). Ciência e Tecnologia de Alimentos, v.22, n.1, p. 24-31, 2002.

SOUZA, C.L.; NEVES, E.C.A.; CARNEIRO, C.A.A.; FARIAS, J.B., PEIXOTO, S.R.S. Avaliação Microbiológica e Físico-Quimica de doce de leite e requeijão produzidos com Leite de Búfala na Ilha de Marajó - Pa. Boletim Centro de Pesquisa de Processamento de Alimentos, Curitiba, v. 20, n. 2, p. 191-202, jul./dez. 2002

VANDERZANT, C. \& SPLITTSTOESSER, D.F. Compendium of methods for the microbiological examination of foods. 3ed. Washington: American Public Health Association, 1992.

\section{Dados do primeiro autor:}

Nome completo: Grasiele Scarmal Madrona

Filiação institucional: Universidade Estadual de Maringá

Departamento: Departamento de Engenharia Química

Função ou cargo ocupado: Professora Assitente

Endereço completo para correspondência: Departamento de Engenharia Química, Universidade

Estadual de Maringá, Av. Colombo, 5790, Zona 7, Maringá - Pr, Cep: 87020900

Telefones para contato: 44-32613863

e-mail: gsmadrona@uem.br 